\title{
Volumetric assessment of the sella turcica: a re-evaluation
}

\author{
J.A. Ortega-Balderas ${ }^{1 *}$, A.B. Acosta-Flores ${ }^{1 *}$, F.J. Barrera ${ }^{1}$, R.A. Lugo-Guillen ${ }^{1}$, \\ M.A. Sada-Treviño², R. Pinales-Razo ${ }^{2}$, A. Quiroga-Garza1', J.H. Martinez-Garza1, \\ R.E. Elizondo-Omaña', S. Guzman-Lopez ${ }^{1}$ \\ ${ }^{1}$ Human Anatomy Department, Facultad de Medicina, Universidad Autónoma de Nuevo León, \\ Monterrey, Nuevo León, México \\ ${ }^{2}$ Radiology and Imaging Department, Facultad de Medicina y Hospital Universitario "Dr. José Eleuterio González", \\ Universidad Autónoma de Nuevo León, Monterrey, Nuevo León, México
}

[Received: 9 August 2021; Accepted: 14 September 2021; Early publication date: 26 October 2021]

Background: The sella turcica volume is widely measured by the Di Chiro-Nelson method. The purpose is to compare the fidelity of a proposed volumetry method vs. the Di Chiro-Nelson method, using computed tomography (CT) images.

Materials and methods: Morphometric examination of 173 CT scans were included, of which $52.6 \%$ were female. The mean age was $53.2 \pm 17.6$ years. Considering the Di Chiro-Nelson method, two measurements were added for each axis in the CT evaluation: length (central, left, and right), width (central, anterior, and posterior), and height (central, left, and right).

Results: The mean measurements were length: central $10.11 \pm 1.44$, left $7.45 \pm$ \pm 1.67 , right $7.53 \pm 1.59$; width: central $12.27 \pm 2.11$, anterior $10.99 \pm 1.92$, posterior $10.10 \pm 1.74$; height: central $7.68 \pm 1.38$, left $7.16 \pm 1.35$, right $7.40 \pm 1.41$. A statistically significant difference between sexes was found only in the anterior width $(p=0.01)$. Using the proposed method, the volume was $342.2 \pm 88.5$ and $378.6 \pm 113.9 \mathrm{~mm}^{3}$, respectively for females and males $(p=0.02)$ vs. $476.1 \pm 132.4$ and $523.8 \pm 186.0 \mathrm{~mm}^{3}(p=0.05)$ using the $\mathrm{Di}$ Chiro-Nelson's method.

Conclusions: Women had significantly smaller sella turcica volume than men. This proposed method considers the sella turcica as a not strictly symmetrical structure and indicates reduced variation between the maximum and minimum values, compared to the Di Chiro-Nelson's. Our findings may be useful for reassessment the volume of the sella turcica as the measurements indicate a higher precision. (Folia Morphol 2022; 81, 4: 1014-1021)

Key words: sella turcica, computed tomography, volumetry, Di Chiro-Nelson method

Address for correspondence: S. Guzman-Lopez, MD, PhD, Department of Human Anatomy, Faculty of Medicine and University Hospital "Dr. José Eleuterio González", Universidad Autónoma de Nuevo León (U.A.N.L.), Monterrey, Nuevo León, México, tel: +52 (81)83-29-41-71, fax: 81 8347-7790, e-mail: dr.santos.anato@gmail.com

*Both authors participated equally in the study and are both in the position of first author

This article is available in open access under Creative Common Attribution-Non-Commercial-No Derivatives 4.0 International (CC BY-NC-ND 4.0) license, allowing to download articles and share them with others as long as they credit the authors and the publisher, but without permission to change them in any way or use them commercially. 


\section{INTRODUCTION}

The sella turcica is a bony structure located in the middle cranial fossa [7]. Its anatomy consists of anterior and posterior clinoid processes and central hypophyseal fossa. The latter is a space formed at the upper surface of the body of the sphenoid bone between the tuberculum sellae and the dorsum sellae $[18,31]$. The pituitary gland is a structure that has an important endocrinological function as the central regulator of the endocrine system, located in the deepest point of the sella turcica [17].

There are pathologies and deviations in its development that increase or decrease the size of the pituitary gland. Likewise, these pituitary gland alterations may modify the size and morphometry of the sella turcica, as their development is closely related [27, 35]. The sella turcica abnormalities are caused by individual variations in shape, and asymmetry in normal subjects, pituitary adenomas, hypothyroidism, empty sella syndrome, acromegaly, tumours, and Sheehan syndrome $[2,7,13$, 27]. It also plays a role in craniofacial abnormalities and the decision making and application of surgical interventions [1, 27, 32, 34], as anatomical knowledge is essential during the procedure to avoid damage [35].

Determining the volume of the sella turcica by imaging studies has been used to infer the pituitary gland volume $[8,28]$ and helps to recognise the normal and anomalous morphology [27]. One of the most widely used volumetry methods is the Di Chiro-Nelson method, in which the length, height, and width are multiplied together and divided in half [8]. However, they utilised radiograph images, and with the improvement of imaging technology, the existing methods have been re-evaluated [21, 27, 35]. We provide a straightforward method, considering the sella turcica as a not strictly three-dimensional symmetrical structure. These measurements play an advantage where magnetic resonance imaging (MRI) is not readily available or contraindicated.

Our objective is to validate a proposed method to determine the volume of the sella turcica and compare it to the Di Chiro-Nelson method using computed tomography (CT) scans. Thus, standardizing the sella turcica volume adds clinical suspicion of pathologies that alter the pituitary gland's size.

\section{MATERIALS AND METHODS}

\section{Research design}

An observational, retrospective and comparative study was performed. Images were obtained in a case consecutive method from the database of the Radiology and Imaging Department of the University Hospital "José Eleuterio González" of the Universidad Autónoma de Nuevo León. Studies were obtained from adult patients without discrimination for age or gender. Those with a history of fractures, tumours, surgical interventions in the skull base, cancer, craniofacial syndromes, congenital structural abnormalities, or conditions that could affect bone metabolism were excluded. This study adheres to the STROBE guidelines for the report of observational studies [30].

\section{Study technique}

All images were acquired using a 64-slice tomograph (General Electric CT99 Light Speed VCT) Software $2978195 \mathrm{VCT}$, with a rotation of $0.4 \mathrm{~s}$ helical acquisition, detector coverage of $20 \mathrm{~mm}, 400 \mathrm{mAs}$ at $120 \mathrm{kV}$; thickness of cut of $0.625 \mathrm{~mm}$, pitch of 0.53: $1 \mathrm{~mm} / \mathrm{rot}$, field of view of 22 to $33 \mathrm{~cm}$. The data obtained were transferred and analysed in a Work Station AW Volume Share2 workstation using multiplanar reformatting with maximum projection intensity and rendering volume. During the measurements, a window range of window width 4000 and window level 1000 was used in a standardised manner in all subjects. The images and measurements were assessed independently by two radiologists with experience in neuroradiology.

The CT scans were measured with Di Chiro-Nelson [0.5 $\times$ (length $\times$ width $\times$ depth)] and our proposed method (Table 1). In our proposed method, we added two measurements parallel to each of the three axes (length, height, and width) (Fig. 1). The volume, according to our method, is obtained by the mean of the three measurements of each axis $[0.5 \times[$ (mean length distances) $\times$ (mean height distances) $\times$ (mean width distances)]. All authors agreed on the bone landmarks, as anatomical variations of the sella turcica shape have been determined.

\section{Ethics approval}

This study was previously reviewed and approved by the ethics and research committees of Hospital Universitario "Dr. Jose Eleuterio Gonzalez" of the Universidad Autónoma de Nuevo León under the registration number AH17-00004, certifying that it adheres to the guidelines of the General Health Law on Health Research in Human Beings of our country, as well as international guidelines and the Declaration of Helsinki. Research and ethics 
Table 1. Comparison of the measurements

\begin{tabular}{|c|c|c|c|}
\hline Di Chiro-Nelson method & Description & Current study [2021] method & Description \\
\hline \multirow[t]{2}{*}{ Length } & \multirow{2}{*}{$\begin{array}{l}\text { The distance on the antero- } \\
\text { posterior axis of the sella turcica } \\
\text { from the back to the tuberculum }\end{array}$} & Central length & $\begin{array}{l}\text { The distance on the anteroposterior axis of the } \\
\text { sella turcica from the dorsum to the tubercle }\end{array}$ \\
\hline & & Left and right length & $\begin{array}{l}\text { The distance from each lateral end of the tubercle } \\
\text { to the lateral end of the posterior clinoid processes }\end{array}$ \\
\hline \multirow[t]{2}{*}{ Height } & \multirow{2}{*}{$\begin{array}{l}\text { The line perpendicular to the line } \\
\text { that measures the length and } \\
\text { that coincides with the deepest } \\
\text { portion of the sella turcica }\end{array}$} & Central height & $\begin{array}{l}\text { The line perpendicular to the centre length of the } \\
\text { sella to the deepest point of the hypophyseal fossa }\end{array}$ \\
\hline & & Left and right height & $\begin{array}{l}\text { The perpendicular distance of the midpoint of the } \\
\text { left and right lengths, respectively to the deepest } \\
\text { point of the sella turcica }\end{array}$ \\
\hline \multirow[t]{2}{*}{ Width } & \multirow{2}{*}{$\begin{array}{l}\text { The lateral-lateral distance of the } \\
\text { highest point of the tubercle of } \\
\text { the sella turcica }\end{array}$} & Central width & $\begin{array}{l}\text { The lateral-lateral distance of the highest point of } \\
\text { the tubercle of the sella turcica }\end{array}$ \\
\hline & & Anterior width and posterior width & $\begin{array}{l}\text { The width of the tubercle and the width of } \\
\text { the dorsum of the sella, respectively }\end{array}$ \\
\hline
\end{tabular}

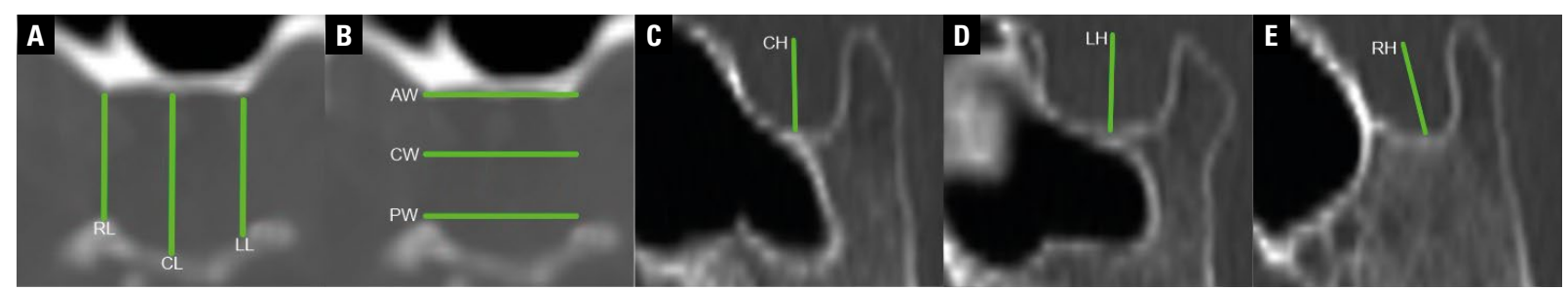

Figure 1. Representation of the measurement variables in the proposed method. Measurements represent the variables described in Table 1. Axial slice of computed tomography; A. Central (CL), right (RL), and left length (LL); B. Central (CW), anterior (AW), and posterior width (PW). Sagittal slice of computed tomography; C. Central height (CH); D. Left height (LH); E. Right height (RH).

committees waived the need for further written consent.

\section{Statistical analysis}

The sample size calculation was made with a formula for estimating a mean in an infinite population resulting in a sample size of 173 studies. Normality tests were performed using the Kolmogorov-Smirnov test. Central tendency and dispersion data were obtained, expressed as mean and standard deviation for parametric data, and as median and minimum and maximum in nonparametric data. The comparisons between the different groups for the categorical variables were made by Pearson's $\chi^{2}$ test and for the numerical variables by the two-tailed Student's t test for the parametric data, and Mann-Whitney $U$ test for the non-parametric data. Parametric (Pearson's) and non-parametric (Spearman's) correlations were performed to evaluate the linear relationship between the numerical variables. A p-value of $<0.05$ was considered statistically significant. Furthermore, for categorical observations, the inter-observer agreement was assessed by the Cohen's Kappa statistic. A $p$ value of $<0.05$ was considered statistically sig- nificant. All the statistical analyses were performed in IBM SPSS Statistics for Mac, version 25 (IBM Corp., Armonk, N.Y., USA).

\section{RESULTS}

A total of 173 CT scans were included, and $52.6 \%$ of the participants were female. The mean age was $53.22 \pm 17.62$ years $(p=0.73)$. All sets of inter-observer reliability analyses resulted in substantial reliability (ICC > 0.85 and $k>0.85$ ). The measurements and volume of the sella turcica as means and stratified by sex are shown in Table 2 .

Statistically significant differences between sexes were found only in the anterior width $(p=0.01)$. The comparison of mean volume between sexes was not statistically different using the Di Chiro-Nelson method ( $p=0.05$ ) but it was when using the proposed method ( $p=0.02$ ) (Table 2 ). We then compared the mean measurements of both methods and we found a significant difference $(p<0.001)$.

The differences in standard deviations of the volume were also higher in the Di Chiro-Nelson method (132.41 $\mathrm{mm}^{3}$ in females and $186 \mathrm{~mm}^{3}$ in males) versus the proposed method $\left(88.53 \mathrm{~mm}^{3}\right.$ and $\left.113.89 \mathrm{~mm}^{3}\right)$. 
Table 2. Measurements for both sexes and comparison by methods

\begin{tabular}{llccccc}
\hline \multicolumn{2}{l}{ Measurement } & Mean \pm SD & Median (minimum-maximum) & Females (mean \pm SD) & Males (mean \pm SD) & P \\
\hline Length & Central & $10.11 \pm 1.44$ & $10.30(4.3-14.2)$ & $10.11 \pm 1.36$ & $10.11 \pm 1.54$ & 0.99 \\
& Right & $7.53 \pm 1.59$ & $7.70(2.9-11.8)$ & $7.32 \pm 1.62$ & $7.68 \pm 1.53$ & 0.06 \\
& Left & $7.45 \pm 1.67$ & $7.40(2.8-12.2)$ & $7.35 \pm 1.77$ & $7.56 \pm 1.55$ & 0.42 \\
\multirow{6}{*}{ Width } & Central & $12.27 \pm 2.11$ & $12.30(7.4-17.5)$ & $12.02 \pm 2.12$ & $12.55 \pm 2.07$ & 0.09 \\
& Anterior & $10.99 \pm 1.92$ & $11.00(5.8-16.2)$ & $10.66 \pm 1.87$ & $11.36 \pm 1.92$ & $0.01^{*}$ \\
& Posterior & $10.10 \pm 1.74$ & $9.90(6.0-14.8)$ & $9.95 \pm 1.77$ & $10.27 \pm 1.70$ & 0.22 \\
Height & Central & $7.68 \pm 1.38$ & $7.50(3.4-11.9)$ & $7.50 \pm 1.23$ & $7.77 \pm 1.51$ & 0.19 \\
& Right & $7.40 \pm 1.41$ & $7.30(3.4-11.1)$ & $7.36 \pm 1.29$ & $7.44 \pm 1.54$ & 0.71 \\
& Left & $7.16 \pm 1.35$ & $7.10(3.0-10.6)$ & $7.12 \pm 1.34$ & $7.19 \pm 1.38$ & 0.72 \\
Volume & Di Chiro's & $\mathbf{4 9 8 . 7 \pm 1 6 1 . 4}$ & $\mathbf{4 9 9 . 6 ( 9 0 . 3 - 1 2 5 4 . 7 )}$ & $\mathbf{4 7 6 . 1} \pm 132.4$ & $\mathbf{5 2 3 . 8} \pm \mathbf{1 8 6 . 0}$ & $\mathbf{0 . 0 5}$ \\
& Proposed & $\mathbf{3 5 9 . 4} \pm \mathbf{1 0 2 . 7}$ & $\mathbf{3 4 8 . 5 ( 8 5 . 6 - 7 7 6 . 2 )}$ & $\mathbf{3 4 2 . 2} \pm \mathbf{8 8 . 5}$ & $\mathbf{3 7 8 . 6} \pm \mathbf{1 1 3 . 9}$ & $\mathbf{0 . 0 2 *}$ \\
\hline
\end{tabular}

All measurements in millimetres. Volume in cubic millimetres, ${ }^{*}$ statistical difference between sexes; SD — standard deviation

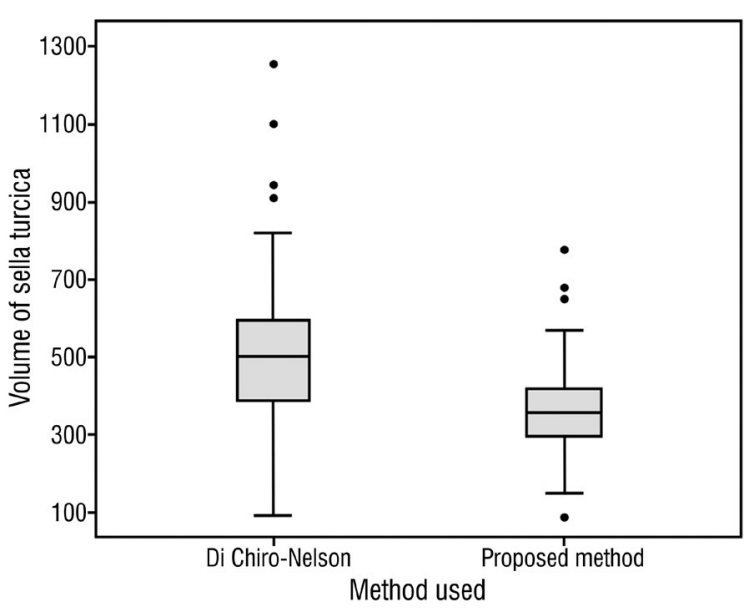

Figure 2. Box plot demonstrating the values obtained by the $\mathrm{Di}$ Chiro-Nelson and the proposed method. The proposed method shows a decrease in the range of the distribution indicating a higher precision of the measurements.

Likewise, the box plot diagram indicates a greater consistency by reducing the variation between the maximum and minimum values, as well as a decrease in the range of the distribution (Fig. 2).

The subjects were stratified according to the age in younger and older than 25 years. A statistically significant correlation is seen between age and the proposed method $(r=0.195) p=0.01$, but not between the Di Chiro-Nelson method $(r=0.130) p=0.08$, in both groups separated by age.

\section{DISCUSSION}

\section{Main findings}

This study is not the first to use CT to determine the volumetry of the sella turcica. However, we deter- mined the volume considering it as an asymmetrical structure, in an adult population without pituitary pathology. Our three-dimensional assessment method demonstrates greater consistency and statistically significant differences between sexes. It reports higher fidelity measurements and lower standard deviations than by the Di Chiro-Nelson method, with two-dimensional radiographs (at the publication time, radiographs were one of the standard techniques for pituitary diseases [5]).

\section{Comparison with previous anatomical studies}

Other authors have proposed modifications to the Di Chiro-Nelson method (Table 3). Hasan et al. (2016) [9] described the morphology and measurements of the sella turcica in CT images stratified by sex, age, and with global data. No significant differences were found for all linear and area measurements of sella turcica between sexes; however, a gradual increase in the size of sella turcica was observed as age advances [10].

Venieratos et al. (2005) [31] utilised dry skulls and focused on the hypophyseal fossa with a geometrical method as they determined the dimensions of the fossa are smaller than those of the sella, and direct measurement of its volume and depth could lead to errors. However, they measured the total volume of the sella with the Di Chiro-Nelson method, obtaining a range between 460 and $1570 \mathrm{~mm}^{3}$. Hlaing et al. (2012) [11] examined adult crania to observe the bony landmarks and to determine the location of a fossa that may occur in the sellar floor. They described four variations and reported a smooth surface in eight 
Table 3. Comparison with previous studies

\begin{tabular}{|c|c|c|c|c|}
\hline Author, year, country & Sample & Mean age [years] & Method & Mean volume $\left[\mathrm{mm}^{3}\right]$ \\
\hline $\begin{array}{l}\text { Yamada et al., 1976, } \\
\text { Japan [33] }\end{array}$ & $\begin{array}{l}570 \text { controls } \\
26 \text { primary hypothyroid patients } \\
34 \text { thyrotoxic patients }\end{array}$ & Controls: 1-60 & Di Chiro-Nelson & $\begin{array}{c}\text { Age 1: } 206 \pm 19 \\
\text { Age 1-25: } 530 \pm 23 \\
\text { Age > 25: } 554 \pm 8 \\
\text { Hypothyroid: } 1,334.4 \pm 101.0 \\
\text { Thyrotoxic: } 558.3 \pm 24.7\end{array}$ \\
\hline $\begin{array}{l}\text { Parks et al., 1978, } \\
\text { USA [20] }\end{array}$ & $\begin{array}{c}\text { Patients with } \\
\text { hypopituitarism: } 3\end{array}$ & $\begin{array}{l}\text { Case } 1: 18.6 \\
\text { Case } 2: 10.4 \\
\text { Case } 3: 6.7\end{array}$ & Di Chiro-Nelson & $\begin{array}{c}1560 \\
1008 \\
840\end{array}$ \\
\hline $\begin{array}{l}\text { Sherif et al., 1989, } \\
\text { Libya [26] }\end{array}$ & $\begin{array}{l}\text { Control: } 17 \\
\text { Sheehan's: } 57\end{array}$ & $41 \pm 8$ & $\begin{array}{l}\text { Statistics volume software and } \\
\text { resistor matrix }\end{array}$ & $\begin{array}{l}922 \pm 155 \\
565 \pm 292\end{array}$ \\
\hline $\begin{array}{l}\text { Bakiri et al., 1991, } \\
\text { Algeria [4] }\end{array}$ & $\begin{array}{l}\text { Control: } 12 \\
\text { Sheehan's: } 54\end{array}$ & $\begin{array}{c}38.3 \pm 3.6 \\
40.21 \pm 1.22\end{array}$ & $\begin{array}{l}\text { Height and length on } \\
\text { their greatest axis }\end{array}$ & $\begin{array}{l}796 \pm 5.6 \\
55.7 \pm 2.7\end{array}$ \\
\hline $\begin{array}{l}\text { Venieratos et al., 2005, } \\
\text { Greece [31] }\end{array}$ & Dry skulls: 20 & NR & Di Chiro-Nelson & 835 \\
\hline $\begin{array}{l}\text { Pittayapat et al., 2015, } \\
\text { Belgium [21] }\end{array}$ & 32 CBCT scans & $26.0 \pm 21.6$ & Maxilim ${ }^{\circledR}$ software & NR \\
\hline $\begin{array}{l}\text { Hasan et al., 2016, } \\
\text { Iraq [10] }\end{array}$ & 71 CT images & 33.9 & $\begin{array}{l}\text { Di Chiro Nelson and three differ- } \\
\text { ent heights of the sella turcica }\end{array}$ & 65.3 \\
\hline $\begin{array}{l}\text { Yasa et al., 2017, } \\
\text { Turkey [35] }\end{array}$ & 177 CBCT scans & $11-73$ & NR & NR \\
\hline $\begin{array}{l}\text { Taner et al., 2019, } \\
\text { Turkey [27] }\end{array}$ & 80 & $\begin{array}{l}\text { F: } 26.6 \pm 8.6 \\
\text { M: } 27.5 \pm 9.0\end{array}$ & Di Chiro-Nelson & $\begin{array}{c}951.3 \pm 278.5 \\
1102.0 \pm 285.3\end{array}$ \\
\hline $\begin{array}{l}\text { Ugurlu et al., 2020, } \\
\text { Turkey [29] }\end{array}$ & $\begin{array}{c}\text { Control: } 15 \\
\text { Patients with maxillary } \\
\text { impacted canines: } 73\end{array}$ & $20.01 \pm 6.53$ & $\begin{array}{c}\text { Own method } \\
\text { (19 measurements) }\end{array}$ & NR \\
\hline $\begin{array}{l}\text { Current study, 2021, } \\
\text { Mexico }\end{array}$ & Control: 173 CT scans & $\begin{array}{l}\text { F: } 52.8 \pm 18.3 \\
\text { M: } 53.6 \pm 17.0\end{array}$ & $\begin{array}{l}\text { Proposed method } \\
\text { ( } 9 \text { measurements) }\end{array}$ & $\begin{array}{c}\text { F: } 342.2 \pm 88.5 \\
\text { M: } 378.6 \pm 113.9\end{array}$ \\
\hline
\end{tabular}

$\mathrm{M}$ - male; F — female; NR — not reported; CBCT — cone-beam computed tomography; CT — computed tomography

of the 205 crania. A single posterior fossa was the most common feature, which they described for the first time. We consider these findings to support the reason to measure depth in three different points to have a closer real volume of the sella turcica by taken the anatomical variations into consideration.

Yasa et al. (2017) [35] established the mean distances of length, depth, diameter, and the interclinoid distance of the sella turcica in 177 subjects. No statistically significant difference was found between sexes, but there were statistically significant differences between ages. Our proposed method also identified similar central measurements and a statistically significant correlation between age groups.

Taner et al. (2019) [27] assessed the volume of sella turcica by cone-beam CT in healthy adults. They did not find statistically significant differences between sexes for any Di Chiro-Nelson's method measurements; however, a significant difference was established in volume $(p=0.003)$, which was higher in men. Our proposed method showed statistically significant differences between sexes in the anterior width $(p=0.01)$ and in the volume $(p=0.02)$.

Pittayapat et al. (2015) [21] developed a high precision system for the sella turcica identification using Maxilim ${ }^{\circledR}$ software in 32 subjects. They also focused on orthodontics as the sella point is a reference for the evaluation of the longitudinal growth of patients and their treatment [21]. Our method does not include high precision technology, yet an advantage is that it could be easily replicated with $\mathrm{CT}$ images.

\section{Comparison with previous clinical studies}

Ugurlu et al. (2019) [29] performed a three-dimensional morphometric analysis of the pituitary fossa with cone-beam CT studies with 19 measurements in subjects with maxillary impacted canines and controls. Only the right sella length differed among the three groups $(p<0.05)$ [29]. 
Studies have also determined the volume of the sella turcica in endocrinological diseases. Yamada et al. (1976) [33] compared the size of the sella turcica in normal subjects and patients with primary hypothyroidism and hyperthyroidism. They determined the volume increased with age, and after 25 years of age, remained constant [33].

A small sella turcica size is one predisposing factor that restricts the pituitary blood supply, contributing to Sheehan syndrome [12]. There are studies that compared the volume between patients and controls $[4,26]$, reporting significantly smaller measurements $(p<0.001)$ in the patients than in the control subjects [4]. Therefore, it is worthy to establish mean volumes (Table 3), to clinically orient with pituitary disease.

A systematic review by Roomaney and Chetty (2020) [21] determined that the craniofacial morphometry affected by genetic syndromes is likely to be associated with abnormal variations of the sella turcica. Clinicians should be aware of the abnormalities and considering the underlying signs and symptoms for medical referral. They also conclude more high-quality studies are needed, with standardised and objective methods to determine the morphology of the sella turcica.

Di Chiro-Nelson's method was the first used to evaluate pituitary pathology indirectly. Undoubtedly, we can now assess it with MRI and laboratory tests. However, in pathologies where there is a change in the pituitary gland's volume, it is relevant to have a reference for the volume of the sella turcica. Our work could be used to establish a relationship between measurements by $\mathrm{CT}$ images and the ones obtained by MRI to standardise an index that supports these diseases' diagnosis.

\section{Limitations of the study}

Our method may present inherent imprecision as it has not been validated by other studies or compared to segmentation software methods. Besides, this model attempts to standardize a structure, representing a simplification, given the intrinsic anatomical variability [36]. Further studies are needed to confirm these as there are variations of normal subjects $[1,27]$, and other abnormal sellar variants, altering sellar volume, such as sellar bridging [9], and variations and morphological types in genetic syndromes (e.g. Williams syndrome) [3]. Also, subjects with dental anomalies and either complete or partial calcifica- tion of interclinoid ligament are highly suggestive of a genetic condition [14, 15]. Although there is evidence the sella turcica linear measurements can be used to estimate the pituitary gland size [25], we cannot translate our method. The differences between our morphometric results and those obtained in other studies may be due to the demographic characteristics and imaging methods. We did not perform intraobserver measurements. MRI grants a better understanding of the patient's anatomy and endocrinological diseases [22]. However, it is not always easy to distinguish tumours from haemorrhage and fat packing [16]. CT is less expensive, has a broader distribution, better bone assessment, and it is useful in patients where MRI is contraindicated [24].

\section{Relevance for the clinical practice}

The diseases that alter the size of the pituitary are not uncommon [22]. Our results indicate smaller volumes compared to the Di Chiro-Nelson method, and they should be taken cautiously, as a small sella turcica may show upward bulging of the sellar content (one adenomas' indirect sign), leading to potential misinterpretation [19], as well as other normal and abnormal variants that may modify the volume $[1,9,27]$.

This study has established a new volume assessment regarding the sella turcica as a variable shape structure enclosing anatomical landmarks. The success in diagnosis and treatment depends on a multicentre management with the integration of internal medicine experts [6]. Nonetheless, the assessment with an anatomical approach provides the clinicians a thorough analysis and better understanding of the related diseases' physiopathology. This is why it is essential to renew the previous methods and consider the sella turcica as a not strictly symmetrical structure. Our findings may be useful to identify the volume of the sella turcica as a component of the integral management of pituitary diseases.

\section{CONCLUSIONS}

We determined a volumetric method with greater consistency among measurements and a narrow standard deviation. The Di Chiro-Nelson method has been used for several years. With the new technologies, it was possible to obtain a three-dimensional view of anatomical structures. This is why it is essential to renew the previous methods and consider the sella turcica as a not strictly symmetrical structure. 
Our findings may be useful to identify the volume of the sella turcica as a component of the integral management of pituitary diseases.

\section{Conflict of interest: None declared}

\section{REFERENCES}

1. Akay G, Eren I, Karadag O, et al. Three-dimensional assessment of the sella turcica: comparison between cleft lip and palate patients and skeletal malocclusion classes. Surg Radiol Anat. 2020; 42(9): 977-983, doi: 10.1007/ s00276-020-02481-z, indexed in Pubmed: 32356044.

2. Atci IB, Yilmaz H, Karagoz Y, et al. Prognosis of hormonal deficits in empty sella syndrome using neuroimaging. Asian J Neurosurg. 2018; 13(3): 737-741, doi: 10.4103/ ajns.AJNS_50_18, indexed in Pubmed: 30283536.

3. Axelsson S, Storhaug K, Kjaer I. Post-natal size and morphology of the sella turcica in Williams syndrome. Eur J Orthod. 2004; 26(6): 613-621, doi: 10.1093/ejo/26.6.613, indexed in Pubmed: 15650071.

4. Bakiri F, Bendib SE, Maoui $R$, et al. The sella turcica in Sheehan's syndrome: computerized tomographic study in 54 patients. J Endocrinol Invest. 1991; 14(3): 193-196, doi: 10.1007/BF03346787, indexed in Pubmed: 1906495.

5. Brown SB, Irwin KM, Enzmann DR. CT characteristics of the normal pituitary gland. Neuroradiology. 1983; 24(5): 259-262, doi: 10.1007/BF00333177, indexed in Pubmed: 6687631.

6. Chiloiro S, Giampietro A, Bianchi A, et al. Diagnosis of endocrine disease: primary empty sella: a comprehensive review. Eur J Endocrinol. 2017; 177(6): R275-R285, doi: 10.1530/EJE-17-0505, indexed in Pubmed: 28780516.

7. De Marinis L, Bonadonna S, Bianchi $A$, et al. Primary empty sella. J Clin Endocrinol Metab. 2005; 90(9): 5471-5477, doi: 10.1210/jc.2005-0288, indexed in Pubmed: 15972577.

8. Di Chiro G, Nelson KB. The volume of the sella turcica. Am J Roentgenol Radium Ther Nucl Med. 1962; 87: 989-1008, indexed in Pubmed: 13885978.

9. Gibelli $D$, Cellina M, Gibelli $S$, et al. Sella turcica bridging and ossified carotico-clinoid ligament: Correlation with sex and age. Neuroradiol J. 2018; 31(3): 299-304, doi: 10.1177/1971400917751036, indexed in Pubmed: 29323624.

10. Hasan H, Alam M, Abdullah Y, et al. 3DCT Morphometric Analysis of Sella Turcica in Iraqi Population. J Hard Tissue Biol. 2016; 25(3): 227-232, doi: 10.2485/jhtb.25.227.

11. Hlaing $Y$, Allan JC, Kramer B. A reappraisal of the hypophysial region of the floor of the sella turcica. Clin Anat. 2012; 25(3): 324-329, doi: 10.1002/ca.21242, indexed in Pubmed: 21853465.

12. Karaca Z, Laway BA, Dokmetas HS, et al. Sheehan syndrome. Nat Rev Dis Primers. 2016; 2: 16092, doi: 10.1038/ nrdp.2016.92, indexed in Pubmed: 28004764.

13. Khawaja NM, Taher BM, Barham ME, et al. Pituitary enlargement in patients with primary hypothyroidism. Endocr Pract. 2006; 12(1): 29-34, doi: 10.4158/EP.12.1.29, indexed in Pubmed: 16524860.

14. Leonardi $R$, Barbato $E$, Vichi $M$, et al. A sella turcica bridge in subjects with dental anomalies. Eur J Orthodont. 2006; 28(6): 580-585, doi: 10.1093/ejo/cjl032.
15. Leonardi R, Farella M, Cobourne MT. An association between sella turcica bridging and dental transposition. Eur J Orthodont. 2011; 33(4): 461-465, doi: 10.1093/ ejo/cjq106.

16. Mansouri A, Symons S, Schwartz M, et al. Quantitative volumetric analysis post transsphenoidal pituitary adenoma surgery. Can J Neurol Sci. 2012; 39(5): 600-604, doi: 10.1017/ s0317167100015328, indexed in Pubmed: 22931700.

17. Mazumdar A. Imaging of the pituitary and sella turcica. Expert Rev Anticancer Ther. 2006; 6 Suppl 9: S15-S22, doi: 10.1586/14737140.6.9s.S15, indexed in Pubmed: 17004852.

18. Muhammed FK, Abdullah AO, Liu Yi. Morphology, incidence of bridging, dimensions of sella turcica, and cephalometric standards in three different racial groups. J Craniofac Surg. 2019; 30(7): 2076-2081, doi: 10.1097/ SCS. 0000000000005964 , indexed in Pubmed: 31490436.

19. Muñoz-López Jl, Hernández Villegas A, Riveros Gilardi B, et al. Pituitary gland: beyond adenomas [Internet]. https:// epos.myesr.org/poster/esr/ecr2017/C-2421 (cited 2021 Feb 10).

20. Parks JS, Tenore A, Bongiovanni AM, et al. Familial hypopituitarism with large sella turcica. N Engl J Med. 1978; 298(13): 698-702, doi: 10.1056/NEJM197803302981302, indexed in Pubmed: 628396.

21. Pittayapat $P$, Jacobs $R$, Odri GA, et al. Reproducibility of the sella turcica landmark in three dimensions using a sella turcica-specific reference system. Imaging Sci Dent. 2015; 45(1): 15-22, doi: 10.5624/isd.2015.45.1.15, indexed in Pubmed: 25793179.

22. Rennert J, Doerfler A. Imaging of sellar and parasellar lesions. Clin Neurol Neurosurg. 2007; 109(2): 111-124, doi: 10.1016/j. clineuro.2006.11.001, indexed in Pubmed: 17126479.

23. Roomaney IA, Chetty M. Sella turcica morphology in patients with genetic syndromes: a systematic review. Orthod Craniofac Res. 2021; 24(2): 194-205, doi: 10.1111/ ocr.12426, indexed in Pubmed: 32920986.

24. Sankhe S, Ambadipudi L, Ketkar R, et al. Imaging of sella: Pituitary adenoma and beyond. J Radiat Cancer Res. 2020; 11(1): 3, doi: 10.4103/jrcr.jrcr_23_19.

25. Sathyanarayana HP, Kailasam V, Chitharanjan S. Sella turcica-Its importance in orthodontics and craniofacial morphology. Dent Res J. 2013; 10(5): 571-575, indexed in Pubmed: 24348611.

26. Sherif IH, Vanderley CM, Beshyah S, et al. Sella size and contents in Sheehan's syndrome. Clin Endocrinol (Oxf). 1989; 30(6): 613-618, doi: 10.1111/j.1365-2265.1989. tb00265.x, indexed in Pubmed: 2591059.

27. Taner L, Deniz Uzuner F, Demirel O, et al. Volumetric and three-dimensional examination of sella turcica by conebeam computed tomography: reference data for guidance to pathologic pituitary morphology. Folia Morphol. 2019; 78(3): 517-523, doi: 10.5603/FM.a2018.0106, indexed in Pubmed: 30444524.

28. Tekiner H, Acer N, Kelestimur F. Sella turcica: an anatomical, endocrinological, and historical perspective. Pituitary. 2015; 18(4): 575-578, doi: 10.1007/s11102-014-0609-2, indexed in Pubmed: 25307180.

29. Ugurlu M, Bayrakdar IS, Kahraman F, et al. Evaluation of the relationship between impacted canines and three-dimensional sella morphology. Surg Radiol Anat. 2020; 
42(1): 23-29, doi: 10.1007/s00276-019-02328-2, indexed in Pubmed: 31501910.

30. Vandenbroucke JP, von Elm E, Altman DG, et al. STROBE Initiative. Strengthening the Reporting of Observational Studies in Epidemiology (STROBE): explanation and elaboration. Epidemiology. 2007; 18(6): 805-835, doi: 10.1097/ EDE.0b013e3181577511, indexed in Pubmed: 18049195.

31. Venieratos D, Anagnostopoulou S, Garidou A. A new morphometric method for the sella turcica and the hypophyseal fossa and its clinical relevance Folia Morphol. 2005; 64(4): 240-247, indexed in Pubmed: 16425149.

32. Yalcin ED. Morphometric analysis of sella turcica using conebeam computed tomography in patients with cleft lip and palate. J Craniofac Surg. 2020; 31(1): 306-309, doi: 10.1097/ SCS.0000000000005881, indexed in Pubmed: 31449220.

33. Yamada T, Tsukui T, Ikejiri K, et al. Volume of sella turcica in normal subjects and in patients with primary hypothyroid- ism and hyperthyroidism. J Clin Endocrinol Metab. 1976; 42(5): 817-822, doi: 10.1210/jcem-42-5-817, indexed in Pubmed: 1270575 .

34. Yasa Y, Bayrakdar IS, Ocak A, et al. Evaluation of sella turcica shape and dimensions in cleft subjects using conebeam computed tomography. Med Princ Pract. 2017; 26(3): 280-285, doi: 10.1159/000453526, indexed in Pubmed: 27855395.

35. Yasa Y, Ocak A, Bayrakdar IS, et al. Morphometric analysis of sella turcica using cone beam computed tomography. J Craniofac Surg. 2017; 28(1): e70-e74, doi: $10.1097 / \mathrm{SCS} .0000000000003223$, indexed in Pubmed: 27922970.

36. Żytkowski A, Tubbs R, Iwanaga J, et al. Anatomical normality and variability: Historical perspective and methodological considerations. Transl Res Anat. 2021; 23: 100105, doi: 10.1016/j.tria.2020.100105. 